\title{
Progressive collapse analysis of a bulk carrier using IACS prescribed and NLFEM derived load — end shortening curves
}

\author{
S. Kitarović, J. Andrić, K. Pirić \& M. Bičak \\ Faculty of Mechanical Engineering and Naval Architecture, University of Zagreb, Zagreb, Croatia
}

\begin{abstract}
This paper considers hull girder ultimate strength of a bulk carrier at its midship section, as determined by an incremental-iterative progressive collapse analysis method prescribed by the IACS Common Structural Rules for Bulk Carriers (IACS CSR-BC). In addition to the originally prescribed load-end shortening curves, curves determined by the nonlinear finite element method analysis (considering the influence of the idealized initial geometrical imperfections) are also considered. Results obtained by both sets of curves are compared and discussed on both local (structural components load - end shortening curve) and global (hull girder ultimate bending capacity and collapse sequence) level, for both sagging and hogging cases.
\end{abstract}

\section{INTRODUCTION}

\subsection{General remarks}

Ship's longitudinal load carrying capacity is commonly expressed in terms of the maximum bending moment attainable at the transverse cross section of the critical longitudinal structural segment. If intensity of the flexural load imposed on the hull girder exceeds this ultimate load carrying capacity level, occurrence of the inter-frame collapse is considered to be imminent, meaning that flexural stiffness of the critical longitudinal segment has been significantly reduced due to the progressive depletion of the load carrying capacity of the longitudinal structural components. Progressive collapse of the longitudinal structural components can be induced either by yielding or buckling. Longitudinal structural segment(s) whose position coincides with the position of the maximum bending moment is commonly identified as the critical segment and the change of its load carrying ability during the progressive increase of the flexural load intensity is evaluated.

Assumption regarding the imminent occurrence of the inter-frame collapse prior to any other feasible global collapse mode ensures that the global structural behavior of the hull girder submitted to flexure can be idealized in accordance with the beam bending theory during the whole collapse process. This implication represents fundamental premise of the simplified incremental-iterative Progressive Collapse Analysis (PCA) approach proposed by Smith (1977), which is considered to be the first among established PCA methods which incorporate more sophisticated consideration of the structural collapse sequence and post-critical load carrying capacity of the components of the hull girder submitted to bending. PCA methods are based on evaluation of the (nonlinear) bending moment to curvature relationship which describes the hull girder progressive collapse (for sagging and/ or hogging cases), which is induced by yielding and/ or various feasible buckling modes of the uncoupled discrete structural components (longitudinal stiffeners with the attached breadth of plating, hard corners and transversely stiffened plating) of the critical segment (between two adjacent transverse web frames).

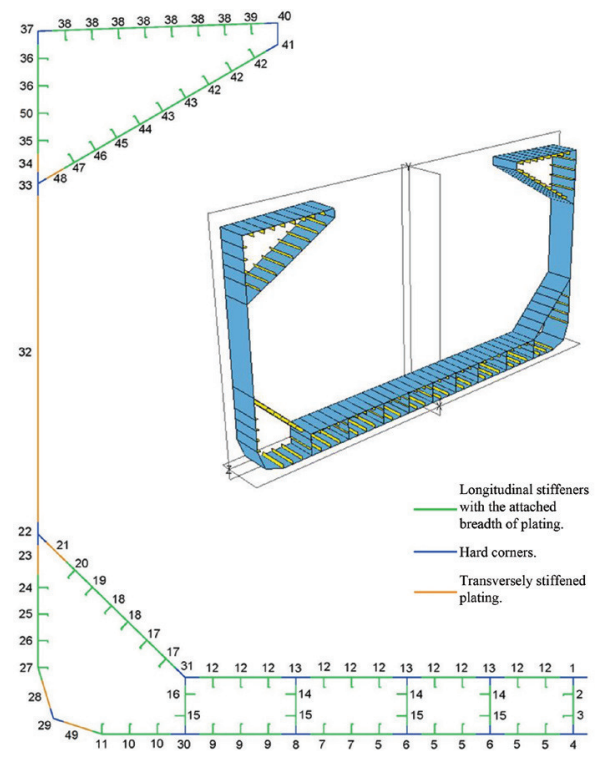

Figure 1. Discrete structural members of the considered hull girder midship section. 
Decoupling of the longitudinal and transverse global structural collapse, see Hughes (1988), enables execution of the PCA separately for each individual longitudinal structural segment and during the hull girder flexure transverse sections are assumed to remain plane, infinitely rigid (in their own plane) and perpendicular on the deflection curve throughout the curvature incrementation process. Within this approach, quality of the obtained results depends significantly on the accuracy of the employed Load-

Table 1. Geometrical and material properties of the cross sectional discrete structural members.

\begin{tabular}{|c|c|c|c|c|c|c|c|c|c|}
\hline $\begin{array}{l}\text { Discrete } \\
\text { member }\end{array}$ & $\begin{array}{l}l \\
(\mathrm{~mm})\end{array}$ & $\begin{array}{l}t p \\
(\mathrm{~mm})\end{array}$ & $\begin{array}{l}b p \\
(\mathrm{~mm})\end{array}$ & $\begin{array}{l}h w \\
(\mathrm{~mm})\end{array}$ & $\begin{array}{l}t w \\
(\mathrm{~mm})\end{array}$ & $\begin{array}{l}b f \\
(\mathrm{~mm})\end{array}$ & $\begin{array}{l}t f \\
(\mathrm{~mm})\end{array}$ & $\begin{array}{l}\text { Plating } \\
\text { material }\end{array}$ & $\begin{array}{l}\text { Stiffener } \\
\text { material }\end{array}$ \\
\hline 1 & 1222.5 & 21.5 & 835 & 250 & 14.5 & 1 & I & АН36 & AH32 \\
\hline 2 & 1222.5 & 14.5 & 575 & 229.2 & 12 & 44.79 & 30.80 & AH32 & AH32 \\
\hline 3 & 1222.5 & 14.5 & 600 & 229.2 & 12 & 44.79 & 30.80 & AH32 & AH32 \\
\hline 4 & 1222.5 & 20.5 & 835 & 275 & 14.5 & 1 & 1 & AH36 & AH 32 \\
\hline 5 & 2445 & 20.5 & 835 & 266.45 & 13 & 54.13 & 33.55 & АH36 & AH32 \\
\hline 6 & 2445 & 20.5 & 835 & 275 & 11.5 & 1 & I & АH36 & AH32 \\
\hline 7 & 2445 & 19.0 & 835 & 266.45 & 13 & 54.13 & 33.55 & АH36 & AH32 \\
\hline 8 & 2445 & 19.0 & 835 & 275 & 11.5 & 1 & I & АH36 & AH32 \\
\hline 9 & 2445 & 17.0 & 835 & 266.45 & 13 & 54.13 & 33.55 & АH36 & AH32 \\
\hline 10 & 2445 & 16.0 & 835 & 266.45 & 13 & 54.13 & 33.55 & АH36 & AH32 \\
\hline 11 & 2445 & 17.0 & 835 & 266.45 & 13 & 54.13 & 33.55 & AH36 & AH 32 \\
\hline 12 & 2445 & 21.5 & 835 & 265.6 & 11 & 50.83 & 34.40 & AH36 & AH36 \\
\hline 13 & 2445 & 21.5 & 835 & 250 & 11.5 & 1 & I & АН36 & AH32 \\
\hline 14 & 2445 & 11.5 & 575 & 150 & 12 & I & I & АH32 & AH32 \\
\hline 15 & 2445 & 11.5 & 600 & 150 & 12 & I & I & АH32 & AH32 \\
\hline 16 & 860 & 11.5 & 575 & 150 & 12 & 1 & I & АH32 & AH32 \\
\hline 17 & 2445 & 19.0 & 800 & 229.2 & 12 & 44.79 & 30.8 & АН36 & AH32 \\
\hline 18 & 2445 & 18.5 & 800 & 229.2 & 12 & 44.79 & 30.8 & АН36 & AH32 \\
\hline 19 & 2445 & 17.5 & 767.5 & 229.2 & 12 & 44.79 & 30.8 & AH32 & AH 32 \\
\hline 20 & 815 & 17.5 & 735 & 229.2 & 12 & 44.79 & 30.8 & AH32 & AH32 \\
\hline 21 & 815 & 17.5 & 662.5 & I & I & 1 & I & AH32 & 1 \\
\hline 22 & 815 & 17.8 & 710 & 350 & 18 & I & I & AH32 & AH32 \\
\hline 23 & 815 & 17.0 & 860 & I & I & 1 & I & АH32 & 1 \\
\hline 24 & 815 & 17.0 & 800 & 229.2 & 12 & 44.79 & 30.8 & АH32 & AH32 \\
\hline 25 & 2445 & 15.5 & 800 & 229.2 & 12 & 44.79 & 30.8 & АH32 & AH32 \\
\hline 26 & 2445 & 15.5 & 800 & 245.8 & 12 & 46.8 & 34.2 & АH32 & AH32 \\
\hline 27 & 2445 & 16.25 & 800 & 245.8 & 12 & 46.8 & 34.2 & АН36 & AH32 \\
\hline 28 & 2445 & 17.0 & 824 & I & I & I & 1 & АН36 & 1 \\
\hline 29 & 2445 & 17.0 & 680 & I & I & I & I & АН36 & 1 \\
\hline 30 & 2445 & 16.5 & 835 & 275 & 11.5 & I & I & АH36 & AH32 \\
\hline 31 & 860 & 20.0 & 817.5 & 250 & 11.5 & I & I & АН36 & AH32 \\
\hline 32 & 815 & 18.5 & 5790 & I & 1 & I & I & AH32 & 1 \\
\hline 33 & 815 & 18.0 & 720 & 300 & 15 & I & I & AH32 & AH32 \\
\hline 34 & 815 & 17.5 & 530 & I & I & 1 & I & AH32 & 1 \\
\hline 35 & 815 & 17.5 & 820 & 324.6 & 13 & 60.36 & 45.4 & AH32 & АH36 \\
\hline 36 & 4075 & 17.0 & 820 & 324.6 & 13 & 60.36 & 45.4 & АH36 & AH36 \\
\hline 37 & 4075 & 17.0 & 410 & 410 & 20 & 1 & I & АН36 & АН 36 \\
\hline 38 & 4075 & 20.0 & 810 & 296.15 & 12 & 53.05 & 43.85 & AH36 & AH36 \\
\hline 39 & 4075 & 20.0 & 500 & 296.15 & 12 & 53.05 & 43.85 & АH36 & AH36 \\
\hline 40 & 4075 & 20.0 & 400 & 325 & 16.5 & 1 & 1 & AH36 & AH36 \\
\hline 41 & 4075 & 17.0 & 400 & 325 & 16.5 & 1 & I & АH36 & AH36 \\
\hline 42 & 4075 & 17.0 & 800 & 265.6 & 11 & 50.83 & 34.4 & АH36 & AH36 \\
\hline 43 & 4075 & 16.0 & 800 & 265.6 & 11 & 50.83 & 34.4 & АН36 & AH32 \\
\hline 44 & 4075 & 16.0 & 800 & 266.45 & 13 & 54.13 & 33.55 & AH32 & AH36 \\
\hline 45 & 4075 & 15.0 & 770 & 266.45 & 13 & 54.13 & 33.55 & AH32 & АH36 \\
\hline 46 & 4075 & 15.0 & 740 & 266.45 & 13 & 54.13 & 33.55 & AH32 & AH36 \\
\hline 47 & 815 & 15.0 & 740 & 266.45 & 13 & 54.13 & 33.55 & AH32 & AH36 \\
\hline 48 & 815 & 15.0 & 586 & 1 & I & 1 & 1 & АH32 & 1 \\
\hline 49 & 2445 & 17.0 & 736.5 & 1 & / & 1 & I & АH36 & I \\
\hline 50 & 4075 & 17.5 & 820 & 324.6 & 13 & 60.36 & 45.4 & AH32 & АH36 \\
\hline
\end{tabular}


end Shortening Curves (LSCs), whose formulations usually implicitly contain influence of the initial structural imperfections. LSCs define load carrying capacity of the respective discrete structural components in a nonlinear elasto-plastic domain, where each LSC corresponds to a particular collapse mode of the component. Peak values of the average longitudinal stress, determined by the respective LSC, represent the ultimate longitudinal load carrying capacity of the individual structural component and transcendence of those values is interpreted as the collapse of the structural components according to the respective collapse mode.

A number of past and contemporary researchers published a myriad of studies aimed to provide appropriate formulations of LSCs considering various types and configurations of structural members with various initial imperfections, imposed with various pure and/or combined in-plane and/or lateral loads and boundary conditions. Most of the recent studies are based on numerical simulations employing geometrically and materially Nonlinear Finite Element Method (NLFEM) analyses, e.g. Xu et al. (2012, 2013), Yanagihara \& Fujikubo (2013), Ozdemir \& Ergin (2013), Badran et al. (2013), Tanaka et al. (2014), Gannon et al. (2012), Tekgoz et al. (2013), Jiang \& Zhang (2014), Doshi \& Vhanmane (2014), Choung et al. (2014), Zhang \& Jiang (2014), although some of the recent studies include experimental testing, e.g. Xu \& Guedes Soares (2012a, b, 2013a, b), Shanmugam et al. (2014).

Since the particular bending load or curvature increment of the PCA within which each structural component reached its ultimate load carrying capacity can be identified, in addition to the ultimate bending moment, PCA methods enable identification of the characteristic structural collapse sequence accounting for the load-shedding effect during the progressive load incrementation. Today, rules of many classification societies and IACS prescribe utilization of the incremental-iterative PCA methods for determination of the hull girder ultimate bending capacity. Detailed overview of the ultimate limit state methodology incorporated into contemporary rules and guidelines of the classification societies and requirements of other concerned regulatory agencies can be found in ISSC (2012).

\subsection{Considered problem}

This paper aims to present comparison of the results obtained by the PCA methodology prescribed by IACS (2012) with the results obtained by the same overall methodological framework but with the IACS LSCs substituted with LSCs derived by the NLFEM analyses. A similar comparison presented in Kitarović et al. (2013), which considered the boxgirder structures described in Dowling et al. (1973), showed that existing IACS LSCs employed within context of the current discretization rules prescribed by the contemporary IACS PCA method are not universally adequate for arbitrary stiffened panel configuration, i.e. that their utilization in case of the stiffened panels with slender plating (between stiffeners) and relatively small number of stiffeners will not provide sufficiently accurate results. Hence, this paper considers a ship hull girder structure comprised of the structural members characterized by much more ship-specific material and geometric properties. For this purpose a midship section of the realistic handymax bulk carrier, designed and built in accordance with the IACS (2012), is used.

Figure 1 displays layout of the longitudinally effective material of the considered midship section and shows division with assigned designations and types for all cross sectional discrete structural members. Table 1 contains all relevant geometrical and material properties of the discrete structural members, where $l$ denotes length of the member, $t p$ is thickness of plating, $b p$ is breadth of the (attached) plating, $h w$ is height of stiffener web, $t w$ is thickness of stiffener web, $b f$ is breadth of stiffener web and $t f$ represents thickness of stiffener flange. Young's modulus of elasticity for both AH32 and AH36 steels is equal to $206 \mathrm{GPa}$, while their yield strength is equal to $315 \mathrm{MPa}$ and $355 \mathrm{MPa}$, respectively.

\section{DISCRETIZED MODELS}

FOR NLFEM ANALYSES

\subsection{Structural modeling and boundary conditions (loads and constraints)}

NLFEM models of the discrete structural members longitudinally enclose two half-spans between transverse framing, see Figures 2 to 4 . Transverse frame was not modeled, yet its effect was incorporated by a boundary conditions imposed on nodes of the transverse section 'B'. All models were uniaxially compressed by a uniform longitudinal displacement imposed on nodes of transverse section 'A', although imposed boundary conditions actually induce bi-axial stress state due to the Poisson effect.

Tables 2 to 4 contain descriptions of the employed boundary conditions, where 0 and 1 denote disabled and enabled DoFs, respectively. All nodes of the transverse section ' $\mathrm{A}$ ' were imposed with the same compressive longitudinal displacement. All those nodes have this translation constrained solely due to the enforced displacement modeling rules of the employed software. Value of the imposed longitudinal displacement was selected so as to cover pre-collapse, collapse and post-collapse response regime during the NLFEM analyses performed in order to generate LSCs. All considered models were discretized using two-dimensional isoparametric 


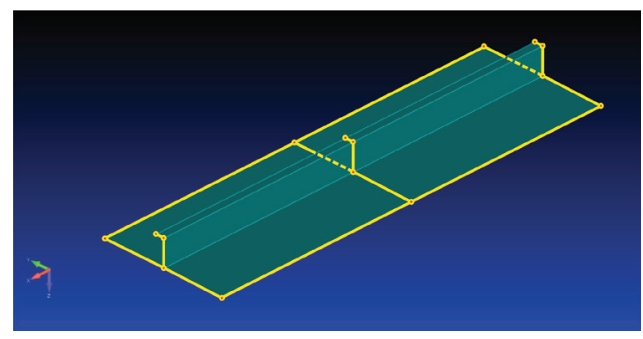

Figure 2. Model of the stiffener with the attached breadth of plating.

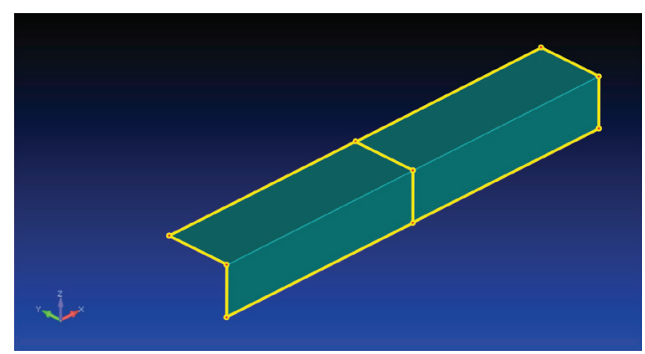

Figure 3. Model of the hard corner.

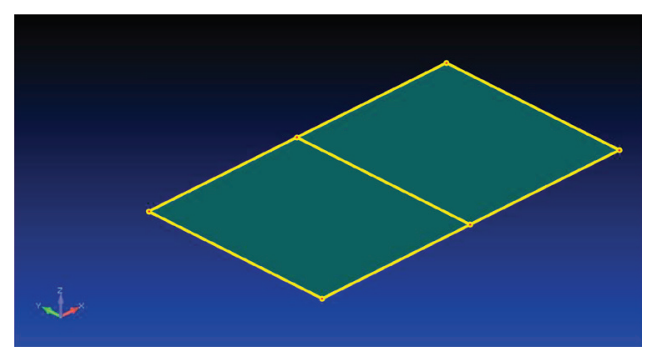

Figure 4. Model of the transversely stiffened plate.

Table 2. Boundary conditions - model of the stiffener with the attached breadth of plating.

\begin{tabular}{|c|c|c|c|c|c|c|}
\hline \multirow[b]{2}{*}{ Node location } & \multicolumn{6}{|c|}{ Degrees of freedom } \\
\hline & Tx & Ty & $\mathrm{Tz}$ & $\mathrm{Rx}$ & Ry & $\mathrm{Rz}$ \\
\hline $\begin{array}{c}\langle\mathrm{A} 1-\mathrm{A} 3],[\mathrm{A} 2-\mathrm{A} 3\rangle,[\mathrm{A} 3-\mathrm{A} 4], \\
{[\mathrm{A} 4-\mathrm{A} 5],\langle\mathrm{C} 1-\mathrm{C} 3],} \\
{[\mathrm{C} 2-\mathrm{C} 3\rangle,[\mathrm{C} 3-\mathrm{C} 4],[\mathrm{C} 4-\mathrm{C} 5] .}\end{array}$ & 0 & 1 & 1 & 1 & 0 & 0 \\
\hline $\begin{array}{l}\langle\mathrm{A} 1-\mathrm{B} 1\rangle,\langle\mathrm{B} 1-\mathrm{C} 1\rangle,\langle\mathrm{A} 2-\mathrm{B} 2\rangle, \\
\langle\mathrm{B} 2-\mathrm{C} 2\rangle .\end{array}$ & 1 & 0 & 1 & 0 & 1 & 0 \\
\hline$\langle\mathrm{B} 1-\mathrm{B} 3\rangle,\langle\mathrm{B} 2-\mathrm{B} 3\rangle,\langle\mathrm{B} 4-\mathrm{B} 5]$. & 1 & 1 & 0 & 1 & 1 & 1 \\
\hline$\langle\mathrm{B} 3-\mathrm{B} 4\rangle$. & 1 & 0 & 1 & 1 & 1 & 1 \\
\hline $\mathrm{A} 1, \mathrm{~A} 2, \mathrm{C} 1, \mathrm{C} 2 .$. & 0 & 0 & 1 & 0 & 0 & 0 \\
\hline B1, B2. & 1 & 0 & 0 & 0 & 1 & 0 \\
\hline B3, B4. & 1 & 0 & 0 & 1 & 1 & 1 \\
\hline
\end{tabular}

Table 3. Boundary conditions - hard corner model.

\begin{tabular}{lllllll}
\hline & \multicolumn{7}{c}{ Degrees of freedom } \\
\cline { 2 - 7 } Node location & Tx & Ty & Tz & $\mathrm{Rx}$ & $\mathrm{Ry}$ & $\mathrm{Rz}$ \\
\hline $\begin{array}{l}\langle\mathrm{A} 1-\mathrm{A} 2],[\mathrm{A} 2-\mathrm{A} 3\rangle, \\
\langle\mathrm{C} 1-\mathrm{C} 2],[\mathrm{C} 2-\mathrm{C} 3\rangle\end{array}$ & 0 & 1 & 1 & 1 & 0 & 0 \\
$\langle\mathrm{~A} 1-\mathrm{B} 1\rangle,\langle\mathrm{B} 1-\mathrm{C} 1\rangle$. & 1 & 0 & 1 & 0 & 1 & 0 \\
$\langle\mathrm{~A} 3-\mathrm{B} 3\rangle,\langle\mathrm{B} 3-\mathrm{C} 3\rangle$ & 1 & 1 & 0 & 0 & 0 & 1 \\
$\langle\mathrm{~B} 1-\mathrm{B} 2\rangle$ & 1 & 1 & 0 & 1 & 1 & 1 \\
$\langle\mathrm{~B} 2-\mathrm{B} 3\rangle$. & 1 & 0 & 1 & 1 & 1 & 1 \\
$\mathrm{~B} 2$. & 1 & 0 & 0 & 1 & 1 & 1 \\
$\mathrm{~B} 1, \mathrm{~B} 3$. & 1 & 0 & 0 & 0 & 1 & 0 \\
$\mathrm{~A} 1, \mathrm{C} 1$. & 0 & 0 & 1 & 0 & 0 & 0 \\
$\mathrm{~A} 3, \mathrm{C} 3$. & 0 & 1 & 0 & 0 & 0 & 0 \\
\hline
\end{tabular}

Table 4. Boundary conditions-transversely stiffened plate model.

\begin{tabular}{lllllll}
\hline & \multicolumn{7}{l}{ Degrees of freedom } \\
\cline { 2 - 7 } Node location & $\mathrm{Tx}$ & $\mathrm{Ty}$ & $\mathrm{Tz}$ & $\mathrm{Rx}$ & $\mathrm{Ry}$ & $\mathrm{Rz}$ \\
\hline$\langle\mathrm{A} 1-\mathrm{A} 2\rangle,\langle\mathrm{C} 1-\mathrm{C} 2\rangle$. & 0 & 1 & 1 & 1 & 0 & 0 \\
$\langle\mathrm{~A} 1-\mathrm{B} 1],[\mathrm{B} 1-\mathrm{C} 1\rangle$, & 1 & 0 & 0 & 0 & 1 & 0 \\
$\langle\mathrm{~A} 2-\mathrm{B} 2],[\mathrm{B} 2-\mathrm{C} 2\rangle$. & & & & & & \\
$\langle\mathrm{B} 1-\mathrm{B} 2\rangle$ & 1 & 1 & 0 & 1 & 1 & 1 \\
$\mathrm{~A} 1, \mathrm{~A} 2, \mathrm{C} 1, \mathrm{C} 2$. & 0 & 0 & 0 & 0 & 0 & 0 \\
\hline
\end{tabular}

finite elements with four nodes (CQUAD4) characterized by the six DoFs at each node. Due to the significant variation in layout and cross sectional geometrical properties of the considered discrete structural members, mesh convergence study was not performed and finest possible mesh density was used for discretization of each member considering the lowest possible element aspect ratio and length to thickness ratio (equal to or greater than unity).

\subsection{Initial structural imperfections}

All metal structures assembled by welding are characterized by the imminent presence of the initial structural imperfections-Initial Distortions (IDs) and residual stresses. While IACS CSR method considers the effect of IDs implicitly within the employed LSCs (effective breadths of plating and/ or effective stiffener web heights are formulated with respect to an average level of IDs), utilization of IDs within the scope of NLFEM analysis requires a more explicit approach. Within framework of the work presented by this paper, discretized model's node positions are dislocated in accordance with the approach based on three different buckling modes of the constituent structural elements, see Hughes $\&$ Paik (2010). Final shape of the imposed IDs is obtained by superposition of all three types of IDs, which are idealized by the periodic functions based 
on the Fourier series. Amplitudes of IDs were determined according to formulations given by Smith et al. (1988), which considers various plate thicknesses. Effects of the residual stresses were not considered within the scope of the presented work.

\subsection{NLFEM analyses and generation of LSCS}

All performed NLFEM analyses were executed using the implicit NX Nastran solver of the FEMAP (2010) software. Material nonlinearity is idealized by the elasto-plastic (bi-linear) material model with disregarded strain hardening/softening, while employed yield function was expressed in terms of the $\mathrm{HMH}$ yield criterion. Newton-Raphson (unmodified) method was employed as utilized strategy for all solutions of the nonlinear stiffness equations.

IACS PCA method was previously encoded into the LUSA module of the OCTOPUS (2009) software and detailed information regarding the obtainable accuracy level of the results can be found in Andrić et al. (2014), where results of the performed benchmarking (covering many different midship section models) were presented. Midship section structural modeling for LUSA, see Figure 1, was performed using MAESTRO (2010) software. In order to enable practical inclusion of the NLFEM derived LSCs within the framework of the IACS PCA method, a B-spline approximation, see Dierckx (1993), was employed using the existing Fortran subroutines of the FITPACK public on-line subroutine library (at: http://www. netlib.org/dierckx/).

\section{RESULTS}

\subsection{Component structures}

NLFEM analyses were performed on four different models of all discrete structural members, in order to generate NLFEM LSCs for four different ID distributions, i.e. for models imposed with zero, slight, average and severe ID amplitude level. Figures 5 to 7 exemplify generated superimposed displays of the NLFEM and IACS LSC plots for the three discrete structural members of the different type. Detailed comparison of the results obtained according to NLFEM (average ID level) and IACS LSCs was performed for all discrete structural members on the ultimate strength (LSC's maximum) level. In that respect, Figures 8 to 11 display obtained relative differences organized according to the structural member's type and the respective IACS collapse mode, where $\%=\left(\sigma_{\text {ult }}\right.$ NLFEM $\left./ \sigma_{\text {ult }}^{\text {IACS }}-1\right) * 100$. Table 5 gives calculated mean absolute differences between obtained ultimate strengths according to NLFEM analyses and IACS collapse modes, where all considered discrete structural members are duly included in a corresponding figure(s).

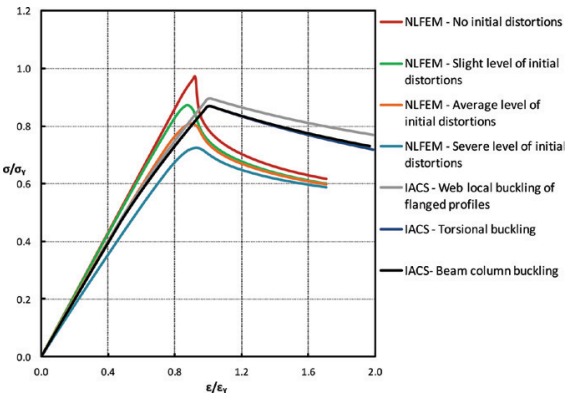

Figure 5. Comparison of the NLFEM and IACS LSCs calculated for discrete structural member 7 (stiffener with the attached breadth of plating).

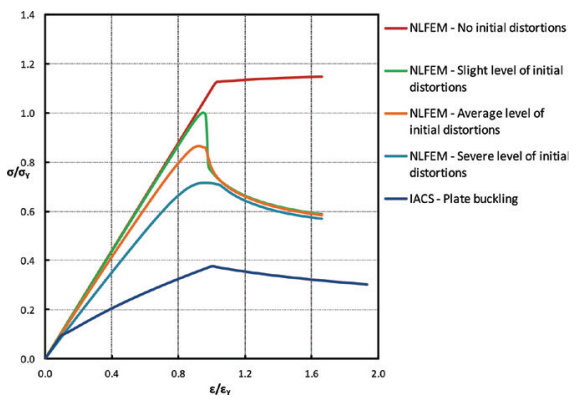

Figure 6. Comparison of the NLFEM and IACS LSCs calculated for discrete structural member 28 (transversely stiffened plate).

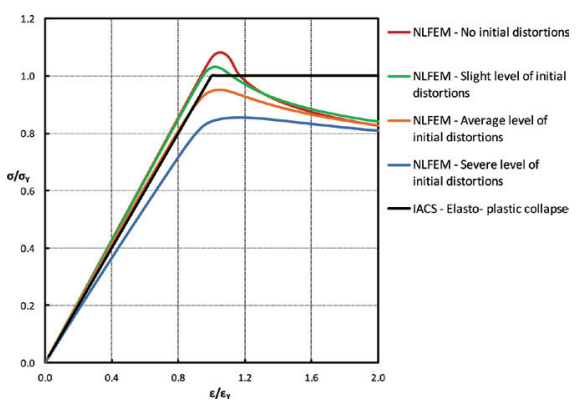

Figure 7. Comparison of the NLFEM and IACS LSCs calculated for discrete structural member 22 (hard corner).

Obtained results organized into superimposed plots of the NLMKE and IACS LSCs imply that relatively small difference can be noted within the pre-collapse response range for all discrete structural members except for the transversely stiffened plating. This difference tends to grow progressively towards the collapse point, especially within the post-collapse response range, where differences are the greatest.

Figures 8 to 12 show that the great majority of the IACS LSCs provide optimistic results (negative relative difference) with respect to the NLFEM 
LSCs. This is especially true for the hard corner structural members, while opposite trend can be noted for the transversely stiffened plating.

It should be noted that significant discrepancies among the NLFEM and IACS LSCs can be observed for the transversely stiffened plating, see Figures 6 and 12 and Table 5, while the smallest difference characterizes stiffeners with the attached breadth of plating, especially for the beam column buckling LSCs, see Figures 5 and 8 to 10 and Table 5 .

\subsection{System structure}

Hull girder ultimate strength analyses of the considered structure in both sagging and hogging flexure were performed employing both IACS prescribed and NLFEM derived LSCs. Obtained results in terms of the hull girder ultimate vertical bending moment are given by Table 6, where relative difference among the obtained results was calculated according to: $\%=\left(\mathrm{M}_{\text {ult }}^{\text {NLFEM }} / \mathrm{M}_{\text {ult }}^{\text {IACS }}-1\right)^{*} 100$. Figure 13 depicts the superimposed vertical bending moment to curvature relationships obtained during

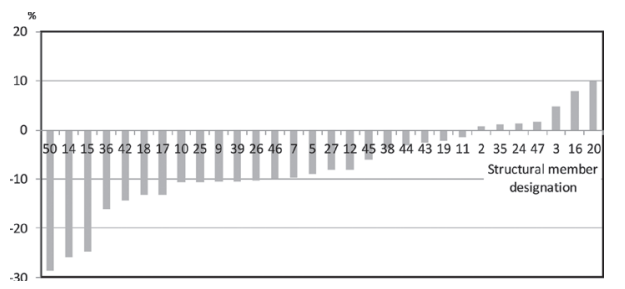

Figure 8. Relative difference between NLFEM and IACS (web local buckling) ultimate strengths for all stiffeners with the attached breadth of plating.

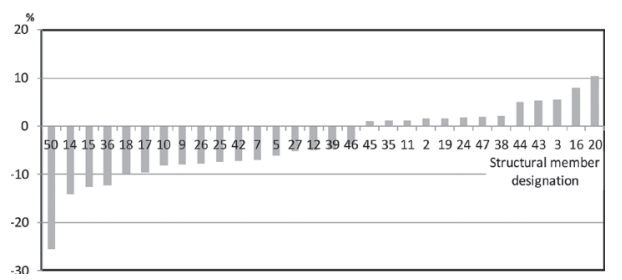

Figure 10. Relative difference between NLFEM and IACS (beam column buckling) ultimate strengths for all stiffeners with the attached breadth of plating.

Table 5. Mean absolute differences in ultimate strength.

\begin{tabular}{|c|c|c|c|c|c|}
\hline \multirow{2}{*}{$\begin{array}{l}\text { Discrete structural } \\
\text { members }\end{array}$} & \multicolumn{3}{|c|}{$\begin{array}{l}\text { Stiffeners with the attached } \\
\text { breadth of plating }\end{array}$} & \multirow{2}{*}{$\begin{array}{l}\text { Hard corners } \\
\begin{array}{c}\text { Elasto plastic } \\
\text { collapse }\end{array}\end{array}$} & \multirow{2}{*}{$\begin{array}{l}\text { Transversely } \\
\text { stiffened plating }\end{array}$} \\
\hline & $\begin{array}{l}\text { Web local } \\
\text { buckling }\end{array}$ & $\begin{array}{l}\text { Torsional } \\
\text { buckling }\end{array}$ & $\begin{array}{l}\text { Beam column } \\
\text { buckling }\end{array}$ & & \\
\hline $\begin{array}{l}\text { Mean absolute } \\
\text { difference }\end{array}$ & $9.3 \%$ & $7.9 \%$ & $6.7 \%$ & $10.0 \%$ & $68.9 \%$ \\
\hline
\end{tabular}

the performed PCAs, along with data and illustrations regarding the obtained collapse sequences.

PCA based on the IACS LSCs showed that during the progressive increase of the hogging curvature deck collapses by yielding at the $0.78 \mathrm{M}_{\text {ult }}$, followed by the gradual yielding of the wing tanks and buckling induced collapse of the bilge tanks. At $0.98 \mathrm{M}_{\mathrm{ult}}$ collapse of the bottom and double bottom girders takes place. During the sagging load incrementation, bucking collapse of the deck wing tanks. Bilge tanks collapsed after the $\mathbf{M}_{u}$ was exceeded. PCA based on the NLFEM LSCs showed that during the progressive increase of the hogging curvature deck collapses by yielding at the $0.82 \mathrm{M}_{\text {ult }}$, followed by the gradual yielding of the wing tanks and buckling induced collapse of the bilge tanks. $\mathbf{M}_{\text {ult }}$ was reached just after the bottom collapsed. During the sagging load incrementation, bucking collapse of the deck occurs first, while the rest of the cross sectional material collapses after the $\mathrm{M}_{\text {ult }}$ was exceeded.

Actually, a very small discrepancy among the results obtained on the system structure level can

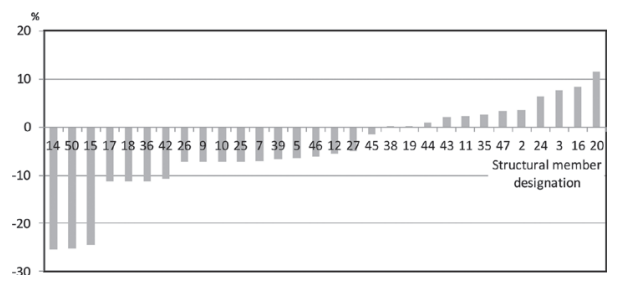

Figure 9. Relative difference between NLFEM and IACS (torsional buckling) ultimate strengths for all stiffeners with the attached breadth of plating.

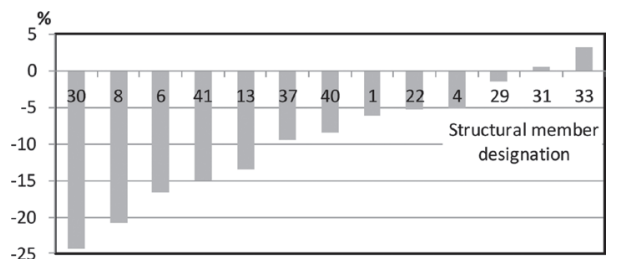

Figure 11. Relative difference between NLFEM and IACS ultimate strengths for all hard corners. occurs at $0.96 \mathrm{M}_{\text {ult }}$, followed by the collapse of the 
be noted. Ultimate bending capacities obtained employing the IACS LSCs are a bit more optimistic with respect to those obtained employing derived NLFEM LSCs, both in sagging and hogging.

\section{CONCLUSIONS}

Generally, it can be concluded that the present IACS LSCs can provide a sufficiently accurate results in

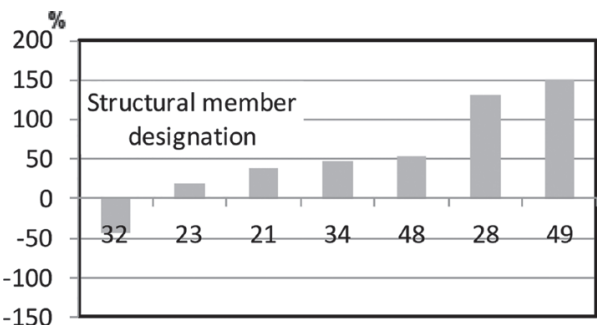

Figure 12. Relative difference between NLFEM and IACS ultimate strengths for all transversely stiffened plates. the ultimate bending capacity analysis of the structures characterized by a more ship-specific material and geometric properties. Although a considerable differences might be observed among the NLFEM and IACS LSCs, which is especially notable for the transversely stiffened plate members, obtained ultimate bending capacity results are in a very good agreement for the considered structure. This can be attributed to a very small content of those elements in the overall system structure. Presumably, a more significant difference between the calculated ultimate bending capacities should be expected in an analysis of the ship structures with considerably higher content of the transversely stiffened plating.

Table 6. Hull girder ultimate vertical bending moment results.

\begin{tabular}{lll}
\hline LSC set & $\begin{array}{l}\mathrm{M}_{\text {ult }}(\mathrm{HOG}) \\
(\mathrm{GNm})\end{array}$ & $\begin{array}{l}\mathrm{M}_{\text {ult }}(\mathrm{SAG}) \\
(\mathrm{GNm})\end{array}$ \\
\hline IACS prescribed & 6.038 & -4.166 \\
NLFEM derived & 5.872 & -4.078 \\
Relative difference & $-2.8 \%$ & $-2.1 \%$ \\
\hline
\end{tabular}

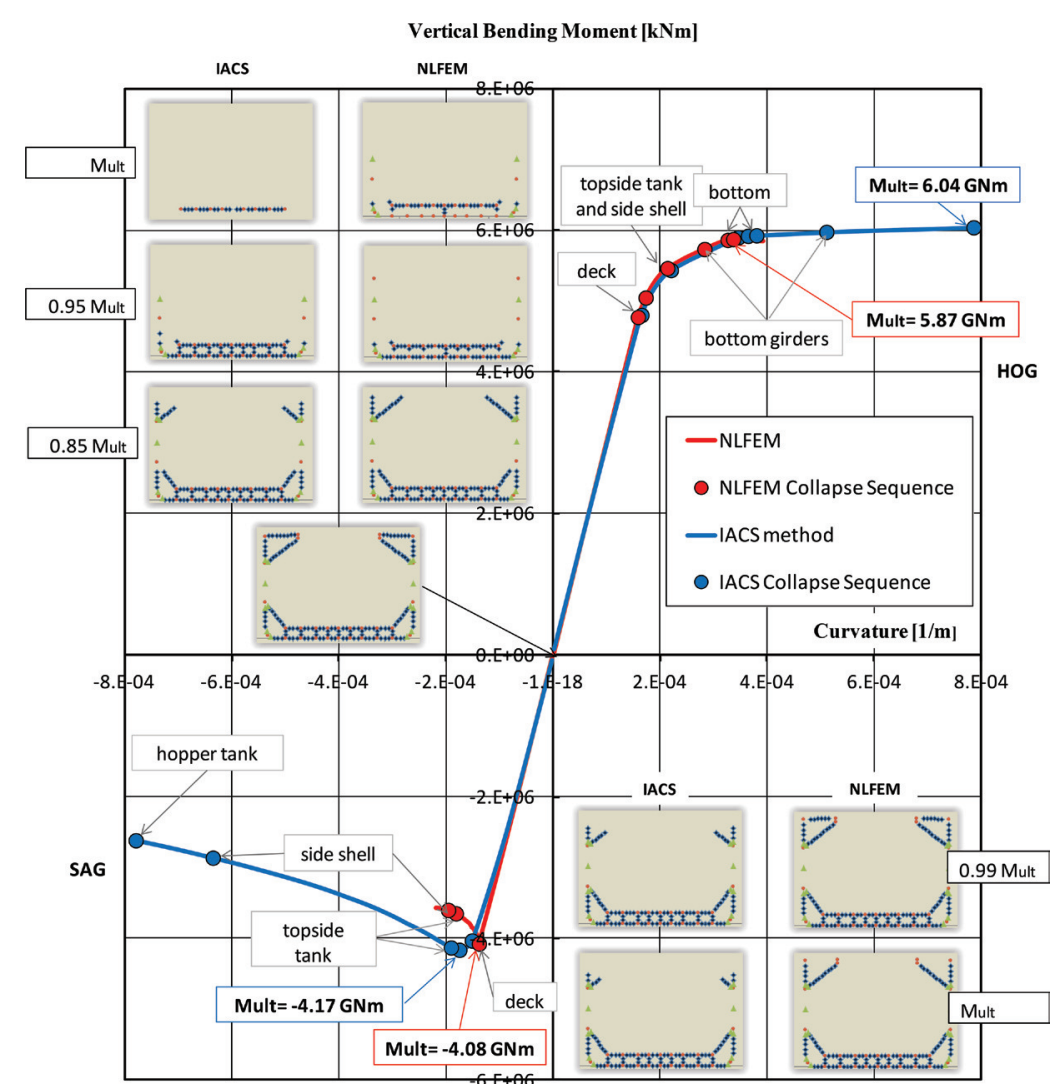

Figure 13. Comparison of the moment to curvature relationships and collapse sequences obtained by the IACS incremental-iterative PCA method based on IACS and NLFEM LSCs. 
Although somewhat optimistic character of the IACS LSCs based PCA results can be generally noted on the system structure level, consideration of the obtained results within the context of the relevant criteria prescribed by IACS (2012) provides an alternative perspective to the considered problem. Since the value of the $\mathrm{M}_{\text {ult }}$ calculated according to IACS prescribed PCA methodology (based on IACS LSCs) is to be reduced by division with the respective safety factor $\left(\gamma_{R}=1.1\right)$, relative differences among the ultimate bending capacities become 7.0\% and $7.7 \%$ for the hogging and sagging cases, respectively. It should be noted that in this case results based on IACS LSCs are actually on the safe side. This implies that a certain safety margin is generally inherent to the results obtainable by the IACS PCA methodology. Although this contributes to the actual structural safety boost, it also simultaneously limits the possibility to fully exploit actually available structural weight minimization potential.

However, work presented by this paper is limited to the consideration of only one midship section configuration and materially-geometric characteristics of its constituent discrete structural members. Hence, obtained results may be considered as a good accuracy measure of the IACS prescribed PCA methodology only when employed upon structures analogous to the considered one. Similarly, applicability of the derived conclusions should be perceived in the same manner.

\section{ACKNOWLEDGEMENTS}

This work has been supported in part by Croatian Science Foundation under the project 8658.

\section{REFERENCES}

Andric, J., Kitarovic, S., Bicak, M. 2014. IACS Incrementaliterative method in Progressive collapse analyses of various hull girder structures. Brodogradnja 65(1): 65-78.

Badran, S.F., Saddek, A.B., Lehet, H.W. 2013. Ultimate strength of $\mathrm{Y}$ and $\mathrm{T}$ stiffeners subjected to lateral loads with three different levels of initial imperfection, Ocean Engineering, 61:12-25.

Choung, J., Park, J-B, Song, C.Y. 2014. Lateral pressure effect on average compressive strength of stiffened panels for in-service vessels, Ships and Offshore Structures, 9(1):110-118.

Dierckx, P. Curve and surface fitting with splines, Oxford University Press, 1993.

Doshi, K. \& Vhanmane, S. 2014. Ultimate Strength of Stiffened Plates Subjected to Longitudinal Compression and Lateral Pressure, Proceedings of the 33rd International Conference on Ocean, Offshore and Arctic Engineering, Volume 4B: Structures, Safety and Reliability, San Francisco, USA.
Dowling, P.J., Chatterjee, S., Frieze, P.A., Moolani, F.M. 1973. Experimental and predicted collapse behaviour of rectangular steel box girders, Proceedings of the International Conference on Steel Box Girder Bridges, Institution of Civil Engineers, London: 77-94.

FEMAP. 2010. Software Documentation. Siemens Product Lifecycle Management Software.

Gannon, L., Liu, Y., Pegg, N., Smith, M.J. 2012. Effect of welding-induced residual stress and distortion on ship hull girder ultimate strength. Marine Structures, 28(1):25-49.

Hughes, O.F. 1988. Ship structural design, Society of Naval Architects and Marine Engineers, New Jersey, USA.

Hughes, O.F. \& Paik, J.K. 2010. Ship structural analysis and design, Society of Naval Architects and Marine Engineers, New Jersey, USA.

IACS. 2012. Common Structural Rules for Bulk Carriers. International Association of Classification Societies.

ISSC. 2012. Technical Committee III.1: Ultimate strength. Proceedings of the 18th International Ship and Offshore Structures Congress, Fricke \& Bronsart (eds), Vol.1. Rostock, Germany.

Jiang, L. \& Zhang, S. 2014. Effect of Pressure on Collapse Behaviour of Stiffened Panel, Proceedings of the $33 r d$ International Conference on Ocean, Offshore and Arctic Engineering, Volume 4A: Structures, Safety and Reliability, San Francisco, USA

Kitarovic, S., Zanic, V., Andric, J. 2013. Progressive collapse analyses of stiffened box-girders submitted to pure bending. Brodogradnja 64(4): 437-455.

MAESTRO. 2010. Software Documentation. DRS-C3 Advanced Technology Center, Stevensville, USA.

OCTOPUS. 2009. Software Documentation. University of Zagreb, Faculty of Mech. Eng. and Nav. Arch.

Ozdemir, M. \& Ergin, A. 2011. Nonlinear buckling behavior of stiffened ship panels, Analysis and Design of Marine Structures, Guedes Soares \& Romanoff (eds), Taylor \& Francis Group, London, UK: 301-308.

Shanmugam, N.E., Dongqi, Z., Choo, Y.S., Arockiaswamy M. 2014. Experimental studies on stiffened plates under in-plane load and lateral pressure, ThinWalled Structures, 80:22-31.

Smith, C.S. 1977. Influence of local compressive failure on ultimate longitudinal strength of a ship's hull. Proceedings of the International Symposium on PRADS, Tokyo: 73-79.

Smith, C.S., Davidson, P.C., Chapman, J.C., Dowling, P.J. 1988. Strength and stiffness of ship's plating under in-plane compression and tension. Transactions of RINA 130: 277-296.

Tanaka S., Yanagihara, D., Yasuoka, A., Harada, M., Okazawa, H., Fujikubo, M., Yao, T. 2014. Evaluation of ultimate strength of stiffened panels under longitudinal thrust, Marine Structures, 36:21-50.

Tekgoz, M., Garbatov, Y., Guedes Soares, C. 2013. Finite element modelling of the ultimate strength of stiffened plates with residual stresses, Analysis and Design of Marine Structures, Guedes Soares \& Romanoff (eds), Taylor \& Francis Group, London, UK:309-317.

Xu, M.C. \& Guedes Soares, C. 2012a. Assessment of the ultimate strength of narrow stiffened panel test specimens, Thin-Walled Structures, 55:11-21. 
Xu, M.C. \& Guedes Soares, C. 2012b. Numerical assessment of experiments on the ultimate strength of stiffened panels, Engineering Structures, 45:460-471.

Xu, M.C. \& Guedes Soares, C. 2013a. Comparisons of calculations with experiments on the ultimate strength of wide stiffened panels, Marine Structures, 31:82-101

Xu, M.C. \& Guedes Soares, C. 2013b. Experimental study on the collapse strength of wide stiffened panels, Marine Structures, 30:33-62.

Xu, M.C., Fujikubo, M. \& Guedes, Soares, C. 2012. Influence of Model Geometry and Boundary Conditions on the Ultimate Strength of Stiffened Panels Under Uniaxial Compressive Loading, Proceedings of the 31st International Conference on Ocean, Offshore and Arctic Engineering, Volume 2: Structures, Safety and Reliability, Rio de Janeiro, Brazil
Xu, M.C., Yanagihara, D., Fujikubo, M. \& Guedes Soares, C. 2013. Influence of boundary conditions on the collapse behaviour of stiffened panels under combined loads, Marine Structures, 34:205-225.

Yanagihara, D. \& Fujikubo, M. 2013. Elastic buckling and elasto-plastic collapse behaviors with torsion of a longitudinal stiffener under axial compression, Analysis and Design of Marine Structures, Guedes Soares \& Romanoff (eds), Taylor \& Francis Group, London, UK:319-328.

Zhang, S. \& Jiang, L. 2014. A Procedure for Non-Linear Structural Collapse Analysis, Proceedings of the 33rd International Conference on Ocean, Offshore and Arctic Engineering, Volume 4 A: Structures, Safety and Reliability, San Francisco, USA. 